OPEN ACCESS

Edited by:

Angelo Labate

University of Catanzaro, Italy

Reviewed by:

Daichi Sone

University College London,

United Kingdom

Lili Long,

Central South University, China

*Correspondence:

Giovanni Battista Dell'Isola giovanni.dellisola@gmail.com

Specialty section:

This article was submitted to

Epilepsy,

a section of the journal

Frontiers in Neurology

Received: 14 September 2021

Accepted: 28 October 2021

Published: 30 November 2021

Citation:

Vinti V, Dell'Isola GB, Tascini G, Mencaroni E, Cara GD, Striano $P$ and Verrotti A (2021) Temporal Lobe Epilepsy and Psychiatric Comorbidity.

Front. Neurol. 12:775781.

doi: 10.3389/fneur.2021.775781

\section{Temporal Lobe Epilepsy and Psychiatric Comorbidity}

\author{
Valerio Vinti ${ }^{1}$, Giovanni Battista Dell'Isola ${ }^{1 *}$, Giorgia Tascini ${ }^{1}$, Elisabetta Mencaroni ${ }^{1}$, \\ Giuseppe Di Cara ${ }^{1}$, Pasquale Striano ${ }^{2,3}$ and Alberto Verrotti ${ }^{1}$
}

${ }^{1}$ Department of Pediatrics, University of Perugia, Perugia, Italy, ${ }^{2}$ Pediatric Neurology and Muscular Diseases Unit, Istituto di Ricovero e Cura a Carattere Scientifico Giannina Gaslini (IRCCS "G. Gaslini") Institute, Genoa, Italy, ${ }^{3}$ Department of Neurosciences, Rehabilitation, Ophthalmology, Genetics, Maternal and Child Health, University of Genoa, Genoa, Italy

Most focal seizures originate in the temporal lobe and are commonly divided into mesial and lateral temporal epilepsy, depending upon the neuronal circuitry involved. The hallmark features of the mesial temporal epilepsy are aura, unconsciousness, and automatisms. Symptoms often overlap with the lateral temporal epilepsy. However, the latter present a less evident psychomotor arrest, frequent clones and dystonic postures, and common focal to bilateral tonic-clonic seizures. Sclerosis of the hippocampus is the most frequent cause of temporal lobe epilepsy (TLE). TLE is among all epilepsies the most frequently associated with psychiatric comorbidity. Anxiety, depression, and interictal dysphoria are recurrent psychiatric disorders in pediatric patients with TLE. In addition, these alterations are often combined with cognitive, learning, and behavioral impairment. These comorbidities occur more frequently in TLE with hippocampal sclerosis and with pharmacoresistance. According to the bidirectional hypothesis, the close relationship between TLE and psychiatric features should lead to considering common pathophysiology underlying these disorders. Psychiatric comorbidities considerably reduce the quality of life of these children and their families. Thus, early detection and appropriate management and therapeutic strategies could improve the prognosis of these patients. The aim of this review is to analyze TLE correlation with psychiatric disorders and its underlying conditions.

Keywords: temporal lobe epilepsy, psychiatric comorbidity, bi-directional hypothesis, hippocampal sclerosis, antiseizure medications (ASMs)

\section{INTRODUCTION}

Temporal lobe epilepsy (TLE) is the most common focal epilepsy (1). According to the International League Against Epilepsy (ILAE) classification (2), TLE can be divided into mesial temporal lobe epilepsy (mTLE) and lateral or neocortical temporal lobe epilepsy (nTLE). mTLE is the most common subtype and seizures originate from the hippocampus, entorhinal cortex, amygdala, and parahippocampal gyrus. The brain structures involved in nTLE are temporal neocortex that includes the superior, medial, and inferior temporal circumvolutions, the temporaloccipital and temporal-parietal junctions and the associative sensorial areas for hearing, visual, and language functions (Figure 1) $(3,4)$. The age at seizure onset for mTLE is lower than nTLE $(10.9$ years and 23.2, respectively). A personal history of febrile convulsion is more frequent in mTLE (1). Patients with TLE generally present focal impaired awareness seizures mainly characterized by the loss of consciousness associated with stereotyped automatisms, language alterations, and 

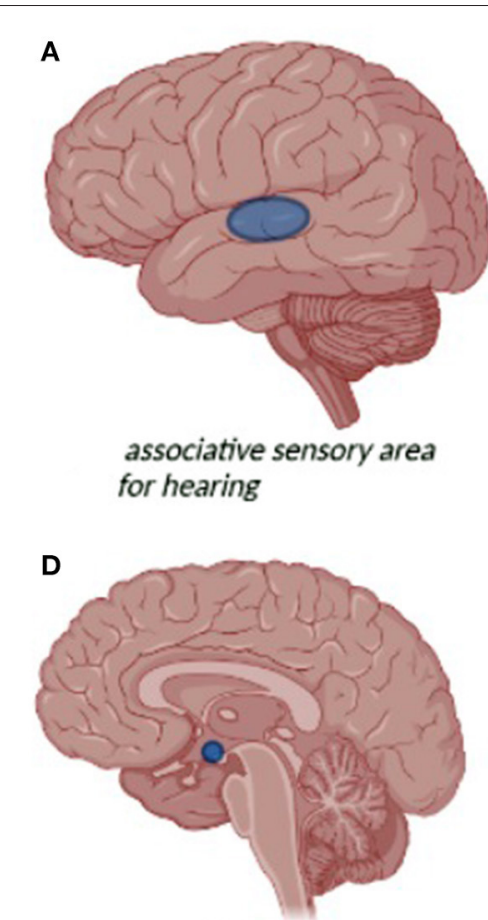

amygdala
B

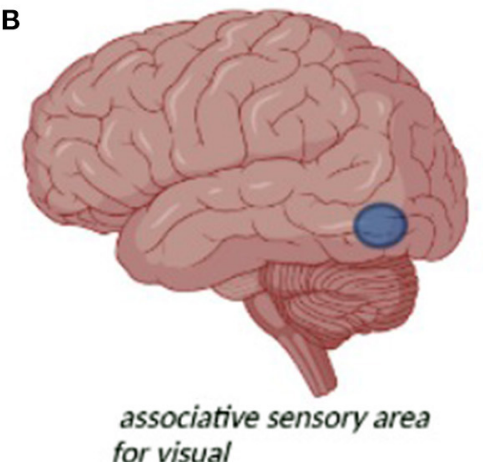

E

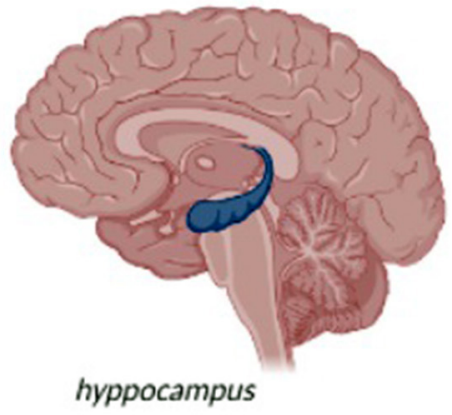

C

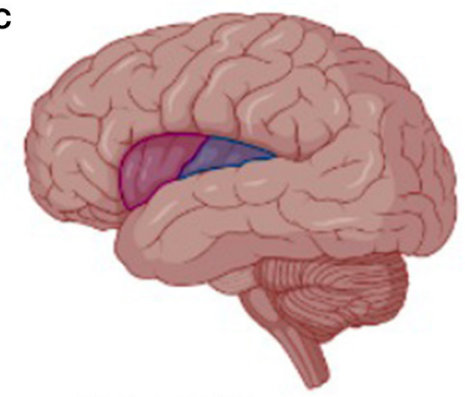

insular cortex

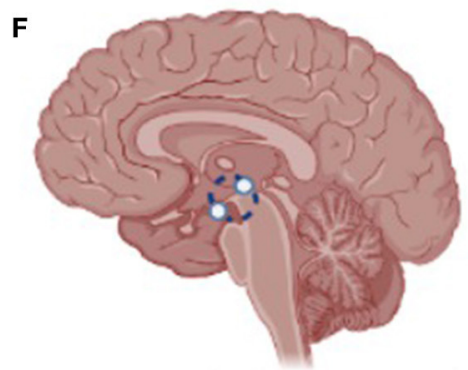

connection between amygdala and periaqueductal gray

FIGURE 1 | Neuroanatomical representation of the temporal lobe and related seizure symptoms and psychiatric symptoms: (A) auditive hallucinations; (B) visual hallucination; (C) visceral-sensory or autonomic symptom; (D) depression; (E) anxiety disorders, depression; (F) avoidance behavior and fear response.

unilateral dystonic posturing. Focal impaired awareness seizure is frequently preceded by epileptic auras or focal aware seizures featured by visceral-sensory or autonomic symptoms and cognitive or emotional manifestations. Epigastric aura is considered a typical feature of $\operatorname{mTLE}(1,3,5)$. Dystonic posturing seems to be associated with basal ganglia involvement, whereas oral automatisms seem to be related to amygdala activation (1, 5-9). Ictal-electroencephalography (EEG) in mTLE is characterized by focal rhythmic activity in the theta range (5$9 \mathrm{~Hz}$ ) with maximum amplitude in the basal temporal electrodes, preceded or not by bilateral hypersynchronous slowdown. nTLE might have a wider distribution at seizure onset with the typical presence of polymorphic activity at $2-5 \mathrm{~Hz}$ in inferiortemporal regions. Interictal-EEG in mTLE shows more frequently unilateral spike-wave, normally located in the anterior temporal region. Paroxystic discharges in medium or posterior-temporal derivations are more commonly found in the interictal-EEG records of nTLE (4). In addition to neurological features, TLE is frequently associated with psychiatric comorbidity. The prevalence of psychiatric disorders in patients with TLE is higher than in generalized epilepsy particularly in the pediatric population (79 vs. 47\%) (10). Anxiety, depression, and interictal dysphoria often combined with cognitive, learning, and behavioral impairment are recurrent psychiatric disorders in the pediatric patients with TLE. Mesial temporal sclerosis (MTS) is the most common structural abnormality associated with TLE. MTS is correlated to a higher prevalence of psychiatric symptoms up to $70 \%$ in pharmacoresistant forms of TLE (11). The aim of this review is to analyze the psychiatric comorbidity of TLE and identify actual management and therapeutic perspectives that might increase the quality of life of these patients.

\section{NEUROLOGICAL FEATURES}

Temporal lobe epilepsy seizures are characterized mainly by behavior arrest and impaired awareness. Focal aware seizures are frequently reported prior to seizure onset. Autonomic or visceral-sensory seizure, characterized by the abdominal or epigastric rising sensation, is more commonly present in mTLE. Other autonomic manifestations are pallor, flushing, cyanosis, alterations in cardiac frequency and rhythm, vomiting, urinary urgency, piloerection or pupillary alterations (3, 4, 12-15). Cognitive and emotional seizures are peculiar of TLE and are characterized by I) dysmnesic features such as déjà vu or jamais vu, II) cognoscitive features with a misperception of internal or external reality, III) emotional features such as panic attacks and behavioral changes, IV) illusions and hallucinations that might set visual, auditive, or olfactory auras $(3,12,14)$. Approximately $70 \%$ of focal aware seizures are followed by the impaired awareness associated with various 
clinical features (3). Focal to bilateral tonic-clonic seizures may occur in about $60 \%$ of patients with TLE (4). Oroalimentary automatisms and manual stereotypes movements are described in $40-80 \%$ of TLE. Particularly, oral alimentary automatism can be associated with amygdala and anterior temporal region involvement $(3,12,16)$. Ictal speech, characterized by intelligible, well-articulated, linguistically correct language during crisis, is observed especially in non-dominant TLE, whereas in dominant TLE is more frequent to observe ictal aphasia and verbal automatisms (3). Unilateral dystonic posturing is more common in MTLE (1). The head deviation is common but not exclusive of TLE with supra-Sylvian structures and frontal lobe involvement $(14,17,18)$. Postictal period is commonly present with a lower frequency in nTLE compared with mTLE (23.5 vs. $85 \%)$ and it is characterized by a confusional state sometimes combined with language alterations or psychiatric symptoms $(4,19)$.

\section{PSYCHIATRIC COMORBIDITY}

Psychiatric symptoms are a common comorbidity of epilepsy (20) especially of TLE occurring in more than half of the cases. However, these manifestations are often misunderstood with a consequent reduction of quality of life of the patients. While ictal disorders are directly related to seizures, interictal psychiatric disorders may occur independently in the context of epilepsy (21). Filho et al. (22) in a study conducted on 170 patients with mTLE detected mood disorders in $25.8 \%$ of cases followed by the psychotic disorders $(15.8 \%)$ and anxiety disorders (14.1\%). Whereas, according to Ertem et al. (23), anxiety disorders resulted the most common psychiatric comorbidity (23\%), followed by mood disorders (17\%), psychotic disorders (13\%), and somatoform disorders (3\%). Seizures worsening and the increasing of seizure frequency are risk factors for psychopathology. Polytherapy with antiseizure medications (ASMs) has been associated with a major risk of behavioral and emotional features. Moreover, familiarity with psychiatric disorders and family disruption are predictors of psychopathology. Hippocampal sclerosis can be associated with an increased risk of frontotemporal network dysfunction resulting in the psychiatric comorbidity. Psychiatric symptoms can occur before and after seizure. Premonitory symptoms, occurring at least $30 \mathrm{~min}$ before a seizure, are frequently described as irritability, depression, headache, "euphoria," and confusion (19). About $44 \%$ of children with TLE are considered at-risk for depression, while $22 \%$ are considered in the clinical significative range (24). Depression and TLE are supposed to have similar physiopathology with common involvement of hippocampus, amygdala, and long-range frontal lobe projections (24-28). The amygdala is determinant in the experience of fear and its autonomic and endocrine responses. Instead, the connection between the amygdala and periaqueductal gray is implicated mainly in avoidance behavior and fear responses. The hippocampus is important in the re-experiencing of fear. Activation of fear circuits is a major hypothesis for explaining symptoms in anxiety disorders (29-31). MRI volumetric studies have found decreased volumes of the amygdala and hippocampus in the recurrent and chronic untreated depression $(26,32)$. Increasing amygdala volumes, particularly on the left side, are associated with depression severity among patients with TLE (33-36). These findings may be due to enhanced regional blood flow and vascular volume as detected by the positron emission tomography (PET) (37) or secondary to dendritic remodeling with increased branching of amygdaloid neurons (38). Patients with TLE and aggressive episodes, such as interictal dysphoric depression manifestation, had a decrease of gray matter mainly in the left frontal lobe (39). Attention deficit hyperactivity disorder (ADHD) is a common comorbidity of childhood epilepsy, but the neuroanatomical correlation of ADHD with epilepsy has yet to be comprehensively characterized. High frequency of seizures and nocturnal crisis may alter attention during the day and worsen ADHD symptoms. In patients with TLE, alterations in attentional control may be charged to structural abnormalities outside the temporal lobe involving frontostriatal connections (40). The greatest deficits appear in divided attention, selective attention, and set shifting that requires a high level of processing resources. In contrast, sustained attention is less compromised and dual-task performance appears to be normal in the patients with TLE (41). Cognitive and behavioral disorders occur in almost $50 \%$ of patients with dysphoric symptoms and usually begin within $24-72 \mathrm{~h}$ postictally. Psychosis is less frequent (2$6 \%)$ and usually follows clusters of focal impaired awareness seizures. This disorder continues for 9-10 days on average postictally and sometimes it can last up to 3 months (19). Autism spectrum disorders (ASDs) are frequent comorbidities in childhood and adolescent epilepsies. According to Chez et al. $60.7 \%$ of children with ASD present epileptiform activity in sleep frequently localized over the right temporal region (42). EEG abnormalities appear to be more frequent in regressive autism (43). The ILAE estimates an overall prevalence of ASD in the epileptic population of $\sim 20 \%$, whereas the prevalence in the general pediatric population is $\sim 1 \%(43,44)$. The prevalence of ASD is the highest in cases with epilepsy accompanied by intellectual disability $(45,46)$. Children with ASD and epilepsy have greater motor difficulties, developmental delays, and behavioral problems than ASD cases without epilepsy (47). The causes of ASD are extremely variable and are sometimes common to epilepsy (48). Increasing evidence suggests that common genetic abnormalities may be associated with both epilepsy and autism $(49,50)$. Alterations in the mTOR pathway may lead to hyperplasticity and contribute to expression of the epilepsy-ASD comorbidity (51). According to Keown et al. (52) the enhanced local visual processing in the autistic patients may be due to the enhanced local connectivity in primary visual and extrastriate cortices, extending into the temporal lobe. Hyperconnectivity of the mesial temporal lobe has as well-been described in TLE (53-55). A diagnosis challenge is represented by psychogenic non-epileptic seizures (PNES), which are conversion disorder that is often misdiagnosed in 5-33\% of patients considered affected by refractory epilepsy $(56,57)$. PNES mainly affect adults but can also occur in children, especially in patients with a history of multiple psychiatric diagnoses (58-60). 


\section{FROM CLASSIC PARADIGM TO BIDIRECTIONAL HYPOTHESIS}

For several years, the "classic paradigm" explained the correlation between neurobehavioral comorbidity and epilepsy using lesionrelated model (61). Indeed, according to this model, epilepsy comorbidity should be consequent to the epilepsy syndrome and its characteristics (etiology, onset, frequency, and treatment). The improvement in cognitive, neuroimaging, and clinical research highlighted neurobehavioral features heterogeneity leading to a challenge to the classic paradigm (62). For example, executive dysfunction, long considered as a pathognomonic feature of the frontal lobe epilepsy, has also been highlighted in the forms of TLE. Indeed, this feature is related to neurobiological influences exerted directly by the frontal lobe and/or indirectly through broader network connectivity (63-67). Neuroimaging studies conducted in patients with TLE showed different abnormalities involving networks disruption far from the primary seizure generation area. Particularly in patients with drug-resistant epilepsy, early-onset seizures can alter white matter development especially involving frontotemporal connections. Long disease durations in focal epilepsy syndromes such as TLE, can also lead to widespread age-accelerate cortical thinning, compounding global cognitive, memory, and processing speed impairments $(68,69)$. Different studies reported that psychiatric features were often present before the epilepsy diagnosis and sometimes they predate seizures onset (70-74). Other studies demonstrated that psychiatric diagnoses might occur before and after epilepsy onset with similar frequency $(58,75,76)$. These findings are in contrast with the classic paradigm assuming that neurobehavioral risk increase over epilepsy development and points out the necessity to explore other common pathways (77). According to the "bi-directional hypothesis," behavioral disorders and psychiatric features may be considered not only comorbidity but related to the same pathophysiology of epilepsy (78-83). For instance, temporal lobe dysfunction has been related to mood and anxiety disorders $(84,85)$. Alteration of pathways involved in temporal lobe connections was found in suiciderelated behavior and post-traumatic stress disorder $(29,86)$. Moreover, depression in youth with TLE has a negative impact on epilepsy management and on the overall quality of life due to poor-treatment adherence, different response and tolerance of ASM, and a higher rate of hospitalization and mortality risk (81, 87-90). The close and complex relationship between epilepsy and psychiatric features should lead to considering these conditions not as an individual but in relation to each other $(19,58,70,72,81,91-93)$. The finding of cognitive, behavioral, and brain-imaging alterations in relatives of patients with epilepsy confirms the importance of genetic study not only in the definition of epilepsy but also of associated neuropsychiatric comorbidities (94-98). To date, studies on the impact of genetics on neurobehavioral comorbidities are scarce and limited to syndromic forms of epilepsy (99). In contrast, the study of this correlation in idiopathic forms of epilepsy remains unexplored. In a study of patients with refractory epilepsy, polymorphisms in the brain-derived neurotrophic factor (BDNF) gene were associated with depression, whereas alterations in the catecholomethyltransferase (COMT) gene were associated with anxiety disorders (100). In addition, epigenomic, transcriptomic, and proteomic alterations certainly play a role in the development of mostly unknown neurocognitive comorbidities (62). Environmental factors are also known to be associated with neurobehavioral disorders. The stigma of epilepsy and its prevalence in poorer and less educated settings with under resourced medical services certainly plays a major role in the development of psychiatric comorbidities and overall quality of life (62). Indeed, a higher cognitive level seems to have a protective role against the neurocognitive comorbidities of epilepsy (101). Intervention toward a better lifestyle through education and psychosocial therapy can contribute to the treatment of epilepsy comorbidities. This approach should be implemented in the clinical practice and tailored to the patient epilepsy and neuropsychiatric comorbidities (62).

\section{DIAGNOSIS AND PHARMACOLOGICAL MANAGEMENT OF PSYCHIATRIC COMORBIDITY}

Early recognition of psychiatric features is the first step to guarantee the correct management of this disorder. It is necessary to exclude that symptoms are a consequence of seizures or an adverse effect of ASM. For the most ASMs, remarkably few studies providing robust data on the psychiatric adverse effects in epileptic patients were identified. Barbiturates, Topiramate, Valproate, and Zonisamide have been reported to cause worsening attention $(102,103)$. Phenobarbital, vigabatrin, zonisamide, topiramate, and levetiracetam could be associated with depression (102). When this is suspected, modification or discontinuation of the responsible drug is recommended. Instead, moderate-severe forms of psychiatric comorbidity not related to ASM require early treatment (60). A good seizure control in these patients is essential to improve psychiatric symptoms (60). No large, double-blind, placebocontrolled trials of medications for ADHD were conducted in children with epilepsy. Methylphenidate was used in small trials in children affected by epilepsy and ADHD with an improvement in attention without worsening of seizures (104108). Amphetamine and atomoxetine may reduce ADHD symptoms without increase in seizure frequency, but little data have been collected for these treatments (109). Anxiety and depression treatment is a combination of education, psychotherapy, and medication. Cognitive behavioral therapy and medication are recommended by the American Academy of Child and Adolescent Psychiatry guidelines for moderateto-severe disorder from Bernstein and Shaw (110). The first choice treatment is serotonin reuptake inhibitors (SSRIs) (111). No controlled trials of SSRIs are conducted in children with epilepsy, but studies on fluoxetine and sertraline have shown improvement in anxiety and depression symptoms without adverse effect on the seizure management (112). Tricyclic antidepressants are not effective in children with anxiety and 
depression, contrary at high dose may reduce seizures threshold with worse control of epilepsy. Bupropion and clomipramine have been associated with an increased risk of seizures (113). Treatment of autism spectrum disorder includes educational and behavioral interventions, but a pharmacological approach can be necessary for specific symptoms $(114,115)$. Indeed, pharmacologic treatment is warranted in the autistic patients with epilepsy. In children with ASD who have mood disorders, choosing a medication that also has mood-leveling properties may be useful. Whether there is any benefit in treating a child with ASD and epileptiform discharges in the absence of epilepsy remains debated (44).

\section{SURGICAL APPROACH}

Temporal lobe epilepsy surgery is currently considered safe and successful in the patients with drug-resistant epilepsy. High-resolution magnetic resonance techniques and advances in microsurgery ability have led to the improvement of this therapeutic approach. However, an adequate patient selection with invasive and non-invasive monitoring including psychiatric assessment is necessary $(116,117)$. Resection strategies have been enhanced over time. Initially, anterior temporal lobectomy (ATL) was considered first-line treatment for mTLE. Subsequently, transsylvian Amygdalo-Hippocampectomy (AH) replaced ATL thanks to improved epileptogenic focus identification technics. Instead, patients with nTLE are treated with lateral lesionectomy without ATL with increasingly limited resections. A satisfactory outcome (Engel I/II) is achieved in $84.7 \%$ of patients treated with surgery. Lateral lesionectomy has the highest success rate $(94.1 \%)$, while $\mathrm{AH}$ has the lowest (78.8\%). This result can be related to the multiple comorbidities in children with mTLE. Indeed, patients with mTLE are less likely to achieve seizure freedom independently of the resection strategies (116). The presence of the psychiatric disorders before the surgery predisposes to psychiatric pathology at 2-year follow-up and is not correlated with epilepsy outcome. After microsurgery,

\section{REFERENCES}

1. Maizuliana H, Usui N, Terada K, Kondo A, Inoue Y. Clinical, semiological, electroencephalographic, and neuropsychological features of "pure" neocortical temporal lobe epilepsy. Epileptic Disord. (2020) 22:55-65. doi: 10.1684/epd.2020. 1132

2. Scheffer IE, Berkovic S, Capovilla G, Connolly MB, French J, Guilhoto, et al. ILAE classification of the epilepsies: position paper of the ILAE commission for classification and terminology. Epilepsia. (2017) 58:51221. doi: 10.1111/epi.13709

3. Maillard L, Vignal JP, Gavaret M, Guye M, Biraben A, McGonigal, et al. Semiologic and electrophysiologic correlations in temporal lobe seizure subtypes. Epilepsia. (2004) 45:1590-9. doi: 10.1111/j.0013-9580.2004.09704.x

4. Pascual MR. Temporal lobe epilepsy: clinical semiology and neurophysiological studies. Semin Ultrasound CT MR. (2007) 28:416-23. doi: 10.1053/j.sult.2007.09.004

5. Pfänder M, Arnold S, Henkel A, Weil S, Werhahn KJ, Eisensehr I, et al. Clinical features and EEG findings differentiating mesial from neocortical temporal lobe epilepsy. Epileptic Disord. (2002) 4:189-95. anxiety and depressive disorders decreased, and psychotic disorders increase without statistical significance. De novo psychiatric disorders occurring after surgery represented 52\% of the postoperative psychiatric pathology, $62 \%$ being psychotic disorders. These disorders became more frequent from the first year after surgery, occurring mainly in the patients seizure free (118).

\section{CONCLUSION}

Psychiatric features and TLE are closely related with overlapping risk factors and common etiologies. Alterations and neurotransmission disturbances among critical networks with impaired or aberrant plastic changes might predispose patients with TLE to the development of these symptoms. Mood and anxiety disorders are the most frequent in the pediatric population. Early diagnosis of these disorders can result in better management, ensuring a multidisciplinary approach and, if necessary, appropriate treatment with increased quality of life. Routine psychological and/or psychiatric evaluation should be standard in the comprehensive care of children with epilepsy. Any comorbid psychiatric disorder must be considered in the choice of ASM, taking into consideration their potential positive and negative psychotropic properties.

Finally, advances observed in the neurosurgery particularly in resection strategies have led to additional therapeutic options. The surgical approach, besides improving neurological symptoms, can lead to a reduction in psychiatric comorbidities in these patients.

\section{AUTHOR CONTRIBUTIONS}

VV and GD put forward the conception of the review and wrote the manuscript. AV and EM participated in the proposal of the concept and revised the manuscript. GT, GC, and PS proposed suggestions for revision. All the authors approved the submitted version.
6. O’Brien TJ, Kilpatrick C, Murrie V, Vogrin S, Morris K, Cook MJ. Temporal lobe epilepsy caused by mesial temporal sclerosis and temporal neocortical lesions. A clinical and electroencephalographic study of 46 pathologically proven cases. Brain. (1996) 119:2133-41. doi: 10.1093/brain/119.6.2133

7. Foldvary N, Lee N, Thwaites G, Mascha E, Hammel J, Kim H, et al. Clinical and electrographic manifestations of lesional neocortical temporal lobe epilepsy. Neurology. (1997) 49:757-63. doi: 10.1212/WNL.49.3.757

8. Gil-Nagel A, Risinger MW. Ictal semiology in hippocampal versus extrahippocampal temporal lobe epilepsy. Brain. (1997) 120:183-92. doi: 10.1093/brain/120.1.183

9. Duchowny M, Jayakar P, Resnick T, Levin B, Alvarez L. Posterior temporal epilepsy: electroclinical features. Ann Neurol. (1994) 35:42731. doi: 10.1002/ana.410350409

10. Gaitatzis A, Trimble MR, Sander JW. The psychiatric comorbidity of epilepsy. Acta Neurol Scand. (2004) 110:20720. doi: 10.1111/j.1600-0404.2004.00324.x

11. de Barros Lourenço FH, Marques LHN, de Araujo Filho GM. Electroencephalogram alterations associated with psychiatric disorders in temporal lobe epilepsy with mesial sclerosis: a systematic review. Epilepsy Behav. (2020) 108:107100. doi: 10.1016/j.yebeh.2020.107100 
12. Parra Gómez J, Iriarte Franco J. Valor del registro ictal con vídeo-EEG en la evaluación prequirúrgica de pacientes con epilepsia del lóbulo temporal. Semiología y patrones electroencefalográficos. Rev Neurol. (1999) 28:898908. doi: 10.33588/rn.2809.99008

13. Serrano Castro PJ, Sánchez Álvarez JC, García Gómez TM. Esclerosis temporal mesial (II): manifestaciones clínicas y estudios complementarios. Rev Neurol. (1998) 26:592-7. doi: 10.33588/rn.26152.981031

14. Iriarte Franco J, Viteri Torres C, Artieda González Granda J. Monitorización prolongada de vídeo-EEG. Aplicaciones clínicas. Rev Neurol. (1998) 26:425-31. doi: 10.33588/rn.26151.981046

15. Fernández Torre JL. Auras epilépticas: clasificación, fisiopatología, utilidad práctica, diagnóstico diferencial y controversias. Rev Neurol. (2002) 34:97783. doi: 10.33588/rn.3410.2001259

16. Ebner A, Dinner DS, Noachtar S, Lüders H. Automatisms with preserved responsiveness: a lateralizing sign in psychomotor seizures. Neurology. (1995) 45:61-4. doi: 10.1212/WNL.45.1.61

17. Fakhoury T, Abou-Khalil B, Peguero E. Differentiating clinical features of right and left temporal lobe seizures. Epilepsia. (1994) 35:103844. doi: 10.1111/j.1528-1157.1994.tb02552.x

18. Marks WJ Jr, Laxer KD. Semiology of temporal lobe seizures: value in lateralizing the seizure focus. Epilepsia. (1998) 9:7216. doi: 10.1111/j.1528-1157.1998.tb01157.x

19. Berg AT, Altalib HH, Devinsky O. Psychiatric and behavioral comorbidities in epilepsy: a critical reappraisal. Epilepsia. (2017) 58:1123-30. doi: 10.1111/epi.13766

20. Verrotti A, Carrozzino D, Milioni M, Minna M, Fulcheri M. Epilepsy and its main psychiatric comorbidities in adults and children. J Neurol Sci. (2014) 343:23-9. doi: 10.1016/j.jns.2014.05.043

21. Josephson CB, Jetté N. Psychiatric comorbidities in epilepsy. Int Rev Psychiatry. (2017) 29:409-24. doi: 10.1080/09540261.2017.1302412

22. Filho GM, Rosa VP, Lin K, Caboclo LO, Sakamoto AC, Yacubian EM. Psychiatric comorbidity in epilepsy: a study comparing patients with mesial temporal sclerosis and juvenile myoclonic epilepsy. Epilepsy Behav. (2008) 13:196-201. doi: 10.1016/j.yebeh.2008.01.008

23. Ertem DH, Dirican AC, Aydin A, Baybas S, Sözmen V, Ozturk M, et al. Exploring psychiatric comorbidities and their effects on quality of life in patients with temporal lobe epilepsy and juvenile myoclonic epilepsy. Psychiatry Clin Neurosci. (2017) 71:280-8. doi: 10.1111/pcn.12499

24. Schraegle WA, Titus JB. The relationship of seizure focus with depression, anxiety, and health-related quality of life in children and adolescents with epilepsy. Epilepsy Behav. (2017) 68:115-22. doi: 10.1016/j.yebeh.2016.12.009

25. Keller SS, Baker G, Downes JJ, Roberts N. Quantitative MRI of the prefrontal cortex and executive function in patients with temporal lobe epilepsy. Epilepsy Behav. (2009) 15:186-95. doi: 10.1016/j.yebeh.2009.03.005

26. Sheline YI. Neuroimaging studies of mood disorder effects on the brain. Biol Psychiatry. (2003) 54:338-52. doi: 10.1016/S0006-3223(03)00347-0

27. Focke NK, Yogarajah M, Bonelli SB, Bartlett PA, Symms MR, Duncan JS. Voxel-based diffusion tensor imaging in patients with mesial temporal lobe epilepsy and hippocampal sclerosis. Neuroimage. (2008) 40:72837. doi: 10.1016/j.neuroimage.2007.12.031

28. Kaiser RH, Andrews-Hanna JR, Wager TD, Pizzagalli DA. Large-Scale network dysfunction in major depressive disorder: a meta-analysis of resting-state functional connectivity. JAMA Psychiatry. (2015) 72:60311. doi: 10.1001/jamapsychiatry.2015.0071

29. Hamid H, Ettinger AB, Mula M. Anxiety symptoms in epilepsy: salient issues for future research. Epilepsy Behav. (2011) 22:63-8. doi: 10.1016/j.yebeh.2011.04.064

30. Rogawski MA, Löscher W. The neurobiology of antiepileptic drugs for the treatment of nonepileptic conditions. Nat Med. (2004) 10:68592. doi: $10.1038 / \mathrm{nm} 1074$

31. Stahl SM. Brainstorms: symptoms and circuits, part 2: anxiety disorders. $J$ Clin Psychiatry. (2003) 64:1408-9. doi: 10.4088/JCP.v64n1201

32. Mueller SG, Laxer KD, Schuff N, Weiner MW. Voxel-based T2 relaxation rate measurements in temporal lobe epilepsy (TLE) with and without mesial temporal sclerosis. Epilepsia. (2007) 48:220-8. doi: 10.1111/j.1528-1167.2006.00916.x

33. Richardson EJ, Griffith HR, Martin RC, Paige AL, Stewart CC, Jones J, et al. Structural and functional neuroimaging correlates of depression in temporal lobe epilepsy. Epilepsy Behav. (2007) 10:242-9. doi: 10.1016/j.yebeh.2006.11.013

34. Tebartz van Elst L, Woermann FG, Lemieux L, Trimble MR. Amygdala enlargement in dysthymia-a volumetric study of patients with temporal lobe epilepsy. Biol Psychiatry. (1999) 46:1614-23. doi: 10.1016/S0006-3223(99)00212-7

35. Tebartz van Elst L, Woermann F, Lemieux L, Trimble MR. Increased amygdala volumes in female and depressed humans. A quantitative magnetic resonance imaging study. Neurosci Lett. (2000) 281:1036. doi: 10.1016/S0304-3940(00)00815-6

36. Frodl T, Meisenzahl EM, Zetzsche T, Born C, Groll C, Jäger M, et al. Hippocampal changes in patients with a first episode of major depression. Am J Psychiatry. (2002) 159:1112-8. doi: 10.1176/appi.ajp.159.7.1112

37. Drevets WC. Neuroimaging studies of mood disorders. Biol Psychiatry. (2000) 48:813-29. doi: 10.1016/S0006-3223(00)01020-9

38. Vyas A, Mitra R, Shankaranarayana Rao BS, Chattarji S. Chronic stress induces contrasting patterns of dendritic remodeling in hippocampal and amygdaloid neurons. J Neurosci. (2002) 22:6810-8. doi: 10.1523/JNEUROSCI.22-15-06810.2002

39. Woermann FG, van Elst LT, Koepp MJ, Free SL, Thompson PJ, Trimble $\mathrm{MR}$, et al. Reduction of frontal neocortical grey matter associated with affective aggression in patients with temporal lobe epilepsy: an objective voxel by voxel analysis of automatically segmented MRI. J Neurol Neurosurg Psychiatry. (2000) 68:162-9. doi: 10.1136/jnnp.68.2.162

40. Riley JD, Moore S, Cramer SC, Lin JJ. Caudate atrophy and impaired frontostriatal connections are linked to executive dysfunction in temporal lobe epilepsy. Epilepsy Behav. (2011) 21:80-7. doi: 10.1016/j.yebeh.2011.03.013

41. Hudson JM, Flowers KA, Walster KL. Attentional control in patients with temporal lobe epilepsy. J Neuropsychol. (2014) 8:140-6. doi: 10.1111/jnp.12008

42. Chez MG, Chang M, Krasne V, Coughlan C, Kominsky M, Schwartz A. Frequency of epileptiform EEG abnormalities in a sequential screening of autistic patients with no known clinical epilepsy from 1996 to 2005. Epilepsy Behav. (2006) 8:267-71. doi: 10.1016/j.yebeh.2005.1 1.001

43. Baird G, Simonoff E, Pickles A, Chandler S, Loucas T, Meldrum D, et al. Prevalence of disorders of the autism spectrum in a population cohort of children in South Thames: the special needs and autism project (SNAP). Lancet. (2006) 368:210-5. doi: 10.1016/S0140-6736(06)69041-7

44. Besag F, Aldenkamp A, Caplan R, Dunn DW, Gobbi G, Sillanpää M. Psychiatric and behavioural disorders in children with epilepsy (ILAE task force report): epilepsy and autism. Epileptic Disord. (2016) 18 (Suppl. 1):186. doi: 10.1684/epd.2016.0809

45. Berg AT, Caplan R, Hesdorffer DC. Psychiatric and neurodevelopmental disorders in childhood-onset epilepsy. Epilepsy Behav. (2011) 20:5505. doi: 10.1016/j.yebeh.2010.12.038

46. Amiet C, Gourfinkel-An I, Bouzamondo A, Tordjman S, Baulac M, Lechat $\mathrm{P}$, et al. Epilepsy in autism is associated with intellectual disability and gender: evidence from a meta-analysis. Biol Psychiatry. (2008) 64:57782. doi: 10.1016/j.biopsych.2008.04.030

47. Turk J, Bax M, Williams C, Amin P, Eriksson M, Gillberg C. Autism spectrum disorder in children with and without epilepsy: impact on social functioning and communication. Acta Paediatr. (2009) 98:67581. doi: 10.1111/j.1651-2227.2008.01184.x

48. Betancur C. Etiological heterogeneity in autism spectrum disorders: more than 100 genetic and genomic disorders and still counting. Brain Res. (2011) 1380:42-77. doi: 10.1016/j.brainres.2010.11.078

49. Brooks-Kayal A. Epilepsy and autism spectrum disorders: are there common developmental mechanisms? Brain Dev. (2010) 32:731-8. doi: 10.1016/j.braindev.2010.04.010

50. Tuchman R, Cuccaro M. Epilepsy and autism: neurodevelopmental perspective. Curr Neurol Neurosci Rep. (2011) 11:42834. doi: 10.1007/s11910-011-0195-x

51. Richard AE, Scheffer IE, Wilson SJ. Features of the broader autism phenotype in people with epilepsy support shared mechanisms between epilepsy and autism spectrum disorder. Neurosci Biobehav Rev. (2017) 75:20333. doi: 10.1016/j.neubiorev.2016.12.036 
52. Keown CL, Shih P, Nair A, Peterson N, Mulvey ME, Muller A, et al. Local functional overconnectivity in posterior brain regions is associated with symptom severity in autism spectrum disorders. Cell Rep. (2013) 5:56772. doi: 10.1016/j.celrep.2013.10.003

53. Bernhardt BC, Bernasconi N, Hong SJ, Dery S, Bernasconi A. Subregional mesiotemporal network topology is altered in temporal lobe epilepsy. Cereb Cortex. (2016) 26:3237-48. doi: 10.1093/cercor/bhv166

54. Bonilha L, Nesland T, Martz GU, Joseph JE, Spampinato MV, Edwards JC, et al. Medial temporal lobe epilepsy is associated with neuronal fibre loss and paradoxical increase in structural connectivity of limbic structures. J Neurol Neurosurg Psychiatry. (2012) 83:903-9. doi: 10.1136/jnnp-2012-302476

55. Dinkelacker V, Valabregue R, Thivard L, Lehericy S, Baulac M, Samson S, et al. Hippocampal-thalamic wiring in medial temporal lobe epilepsy: enhanced connectivity per hippocampal voxel. Epilepsia. (2015) 56:121726. doi: 10.1111/epi.13051

56. Benbadis SR, O'Neill E, Tatum WO, Heriaud L. Outcome of prolonged video-EEG monitoring at a typical referral epilepsy center. Epilepsia. (2004) 45:1150-3. doi: 10.1111/j.0013-9580.2004.14504.x

57. Whitehead K, O'Sullivan S, Walker M. Impact of psychogenic nonepileptic seizures on epilepsy presurgical investigation and surgical outcomes. Epilepsy Behav. (2015) 46:246-8. doi: 10.1016/j.yebeh.2015.01.017

58. Hesdorffer DC, Ishihara L, Mynepalli L, Webb DJ, Weil J, Hauser WA. Epilepsy, suicidality, and psychiatric disorders: a bidirectional association. Ann Neurol. (2012) 72:184-91. doi: 10.1002/ana.23601

59. Puka K, Widjaja E, Smith ML. The influence of patient, caregiver, and family factors on symptoms of anxiety and depression in children and adolescents with intractable epilepsy. Epilepsy Behav. (2017) 67:4550. doi: 10.1016/j.yebeh.2016.12.011

60. Dunn DW. Should pediatric neurologists play a role in the management of the most common psychiatric comorbidities in children with epilepsy? Practical considerations. Epilepsy Behav. (2019) 98:314-7. doi: 10.1016/j.yebeh.2018.11.013

61. Baxendale S, Thompson P. Beyond localization: the role of traditional neuropsychological tests in an age of imaging. Epilepsia. (2010) 51:222530. doi: 10.1111/j.1528-1167.2010.02710.x

62. Hermann BP, Struck AF, Busch RM, Reyes A, Kaestner E, McDonald CR. Neurobehavioural comorbidities of epilepsy: towards a network-based precision taxonomy. Nat Rev Neurol. (2021). doi: 10.1038/s41582-021-00555-z. [Epub ahead of print].

63. Laurent A, Artiges E, Mellerio C, Boutin-Watine M, Landré E, Semah F, et al. Metabolic correlates of cognitive impairment in mesial temporal lobe epilepsy. Epilepsy Behav. (2020) 105:106948. doi: 10.1016/j.yebeh.2020.106948

64. Dinkelacker V, Xin X, Baulac M, Samson S, Dupont S. Interictal epileptic discharge correlates with global and frontal cognitive dysfunction in temporal lobe epilepsy. Epilepsy Behav. (2016) 62:197-203. doi: 10.1016/j.yebeh.2016.07.009

65. Hermann B, Hansen R, Seidenberg M, Magnotta V, O'Leary D. Neurodevelopmental vulnerability of the corpus callosum to childhood onset localization-related epilepsy. Neuroimage. (2003) 18:284-92. doi: 10.1016/S1053-8119(02)00044-7

66. Reyes A, Uttarwar VS, Chang YA, Balachandra AR, Pung CJ, Hagler DJ Jr, et al. Decreased neurite density within frontostriatal networks is associated with executive dysfunction in temporal lobe epilepsy. Epilepsy Behav. (2018) 78:187-93. doi: 10.1016/j.yebeh.2017.09.012

67. Hermann B, Conant LL, Cook CJ, Hwang G, Garcia-Ramos C, Dabbs K, et al. Network, clinical and sociodemographic features of cognitive phenotypes in temporal lobe epilepsy. Neuroimage Clin. (2020) 27:102341. doi: 10.1016/j.nicl.2020.102341

68. Galovic M, van Dooren VQH, Postma TS, Vos SB, Caciagli L, Borzì G, et al. Progressive cortical thinning in patients with focal epilepsy. JAMA Neurol. (2019) 76:1230-9. doi: 10.1001/jamaneurol.2019.1708

69. Hermann BP, Seidenberg M, Dow C, Jones J, Rutecki P, Bhattacharya A, et al. Cognitive prognosis in chronic temporal lobe epilepsy. Ann Neurol. (2006) 60:80-7. doi: 10.1002/ana.20872

70. Hesdorffer DC, Hauser WA, Annegers JF, Cascino G. Major depression is a risk factor for seizures in older adults. Ann Neurol. (2000) 47:246-9. doi: 10. 1002/1531-8249(200002)47:2<246::AID-ANA17>3.0.CO;2-E
71. Austin JK, Harezlak J, Dunn DW, Huster GA, Rose DF, Ambrosius WT. Behavior problems in children before first recognized seizures. Pediatrics. (2001) 107:115-22. doi: 10.1542/peds.107.1.115

72. Hesdorffer DC, Hauser WA, Olafsson E, Ludvigsson P, Kjartansson O. Depression and suicide attempt as risk factors for incident unprovoked seizures. Ann Neurol. (2006) 59:35-41. doi: 10.1002/ana.20685

73. Jones JE, Watson R, Sheth R, Caplan R, Koehn M, Seidenberg M, et al. Psychiatric comorbidity in children with new onset epilepsy. Dev Med Child Neurol. (2007) 49:493-7. doi: 10.1111/j.1469-8749.2007.00493.x

74. McAfee AT, Chilcott KE, Johannes CB, Hornbuckle K, Hauser WA, Walker AM. The incidence of first provoked and unprovoked seizure in pediatric patients with and without psychiatric diagnoses. Epilepsia. (2007) 48:107582. doi: 10.1111/j.1528-1167.2007.01108.x

75. Chang YT, Chen PC, Tsai IJ, Sung FC, Chin ZN, Kuo HT, et al. Bidirectional relation between schizophrenia and epilepsy: a population-based retrospective cohort study. Epilepsia. (2011) 52:2036-42. doi: 10.1111/j.1528-1167.2011.03268.x

76. Adelöw C, Andersson T, Ahlbom A, Tomson T. Hospitalization for psychiatric disorders before and after onset of unprovoked seizures/epilepsy. Neurology. (2012) 78:396-401. doi: 10.1212/WNL.0b013e318245f461

77. Keezer MR, Sisodiya SM, Sander JW. Comorbidities of epilepsy: current concepts and future perspectives. Lancet Neurol. (2016) 15:106-15. doi: 10.1016/S1474-4422(15)00225-2

78. Mula M. Epilepsy: bidirectional link between epilepsy and psychiatric disorders. Nat Rev Neurol. (2012) 8:252-3. doi: 10.1038/nrneurol.2012.69

79. Jones JE. Comments on "Key issues in addressing the comorbidity of depression in pediatric epilepsy". Epilepsy Behav. (2015) 46:7. doi: 10.1016/j.yebeh.2015.04.004

80. Korczyn AD, Schachter SC, Brodie MJ, Dalal SS, Engel J Jr, Guekht A, et al. Epilepsy, cognition, and neuropsychiatry (epilepsy, brain, and mind, part 2). Epilepsy Behav. (2013) 28:283-302. doi: 10.1016/j.yebeh.2013.03.012

81. Kanner AM, Schachter SC, Barry JJ, Hesdorffer DC, Mula M, Trimble M, et al. Depression and epilepsy: epidemiologic and neurobiologic perspectives that may explain their high comorbid occurrence. Epilepsy Behav. (2012) 24:156-68. doi: 10.1016/j.yebeh.2012.01.007

82. Lin JJ, Mula M, Hermann BP. Uncovering the neurobehavioural comorbidities of epilepsy over the lifespan. Lancet. (2012) 380:1180-92. doi: 10.1016/S0140-6736(12)61455-X

83. Mula M, Kanner AM. Introduction-Treatment of psychiatric disorders in adults with epilepsy: what every epileptologist should know. Epilepsia. (2013) 54:1-2. doi: 10.1111/epi.12099

84. Krishnan V, Nestler EJ. Linking molecules to mood: new insight into the biology of depression. Am J Psychiatry. (2010) 167:130520. doi: 10.1176/appi.ajp.2009.10030434

85. Zhang H, Chen Z, Jia Z, Gong Q. Dysfunction of neural circuitry in depressive patients with suicidal behaviors: a review of structural and functional neuroimaging studies. Prog Neuropsychopharmacol Biol Psychiatry. (2014) 53:61-6. doi: 10.1016/j.pnpbp.2014.03.002

86. Patel R, Spreng RN, Shin LM, Girard TA. Neurocircuitry models of posttraumatic stress disorder and beyond: a meta-analysis of functional neuroimaging studies. Neurosci Biobehav Rev. (2012) 36:2130-42. doi: 10.1016/j.neubiorev.2012.06.003

87. Smith AW, Mara CA, Modi AC. Adherence to antiepileptic drugs in adolescents with epilepsy. Epilepsy Behav. (2018) 80:307-11. doi: 10.1016/j.yebeh.2017.12.013

88. Christensen J, Vestergaard M, Mortensen PB, Sidenius P, Agerbo E. Epilepsy and risk of suicide: a population-based case-control study. Lancet Neurol. (2007) 6:693-8. doi: 10.1016/S1474-4422(07)70175-8

89. Puka K, Smith ML, Moineddin R, Snead OC, Widjaja E. The influence of socioeconomic status on health resource utilization in pediatric epilepsy in a universal health insurance system. Epilepsia. (2016) 57:45563. doi: 10.1111/epi.13290

90. Salpekar JA, Berl MM, Havens K, Cushner-Weinstein S, Conry JA, Pearl PL, et al. Psychiatric symptoms in children prior to epilepsy surgery differ according to suspected seizure focus. Epilepsia. (2013) 54:107482. doi: 10.1111/epi.12205

91. Petrovski S, Szoeke CE, Jones NC, Salzberg MR, Sheffield LJ, Huggins RM, et al. Neuropsychiatric symptomatology predicts 
seizure recurrence in newly treated patients. Neurology.

(2010) 75:1015-21. doi: 10.1212/WNL.0b013e3181f25b16

92. Kanner AM, Mazarati A, Koepp M. Biomarkers of epileptogenesis: psychiatric comorbidities (?). Neurotherapeutics. (2014) 11:35872. doi: 10.1007/s13311-014-0271-4

93. Ribot R, Kanner AM. Neurobiologic properties of mood disorders may have an impact on epilepsy: should this motivate neurologists to screen for this psychiatric comorbidity in these patients? Epilepsy Behav. (2019) 98:298-301. doi: 10.1016/j.yebeh.2019.01.026

94. Whelan CD, Alhusaini S, O'Hanlon E, Cheung M, Iyer PM, Meaney JF, et al. White matter alterations in patients with MRI-negative temporal lobe epilepsy and their asymptomatic siblings. Epilepsia. (2015) 56:155161. doi: 10.1111/epi.13103

95. Long L, Galovic M, Chen Y, Postma T, Vos SB, Xiao F, et al. Shared hippocampal abnormalities in sporadic temporal lobe epilepsy patients and their siblings. Epilepsia. (2020) 61:735-46. doi: 10.1111/epi.16477

96. Clarke T, Strug LJ, Murphy PL, Bali B, Carvalho J, Foster S, et al. High risk of reading disability and speech sound disorder in rolandic epilepsy families: case-control study. Epilepsia. (2007) 48:225865. doi: 10.1111/j.1528-1167.2007.01276.x

97. Verrotti A, Matricardi S, Di Giacomo DL, Rapino D, Chiarelli F, Coppola G. Neuropsychological impairment in children with rolandic epilepsy and in their siblings. Epilepsy Behav. (2013) 28:108-12. doi: 10.1016/j.yebeh.2013.04.005

98. Hesdorffer DC, Caplan R, Berg AT. Familial clustering of epilepsy and behavioral disorders: evidence for a shared genetic basis. Epilepsia. (2012) 53:301-7. doi: 10.1111/j.1528-1167.2011.03351.x

99. Busch RM, Najm I, Hermann BP, Eng C. Genetics of cognition in epilepsy. Epilepsy Behav. (2014) 41:297-306. doi: 10.1016/j.yebeh.2014.05.026

100. Doherty C, Hogue O, Floden DP, Altemus JB, Najm IM, Eng C, et al. BDNF and COMT, but not APOE, alleles are associated with psychiatric symptoms in refractory epilepsy. Epilepsy Behav. (2019) 94:1316. doi: 10.1016/j.yebeh.2019.02.032

101. Rzezak P, Guimarães CA, Guerreiro MM, Valente KD. The impact of intelligence on memory and executive functions of children with temporal lobe epilepsy: methodological concerns with clinical relevance. Eur J Paediatr Neurol. (2017) 21:500-6. doi: 10.1016/j.ejpn.2016.12.010

102. Afzal K, Anam S, Hunter S. The effects of antiepileptic drugs on pediatric cognition, mood, and behavior. J Pediatr Epilepsy. (2016) 6:3-18. doi: 10.1055/s-0036-1584935

103. Matricardi S, Farello G, Operto FF, Coppola G, Verrotti A. What are the challenges with the pharmacological management of epilepsy in patients with attention deficit hyperactivity disorder (ADHD)? Expert Opin Pharmacother. (2020) 21:737-9. doi: 10.1080/14656566.2020.1732351

104. Rheims S, Herbillon V, Villeneuve N, Auvin S, Napuri S, Cances C, et al. ADHD in childhood epilepsy: clinical determinants of severity and of the response to methylphenidate. Epilepsia. (2016) 57:106977. doi: 10.1111/epi.13420

105. Santos K, Palmini A, Radziuk AL, Rotert R, Bastos F, Booij L, et al. The impact of methylphenidate on seizure frequency and severity in children with attention-deficit-hyperactivity disorder and difficult-to-treat epilepsies. Dev Med Child Neurol. (2013) 55:654-60. doi: 10.1111/dmcn.12121

106. Feldman H, Crumrine P, Handen BL, Alvin R, Teodori J. Methylphenidate in children with seizures and attention-deficit disorder. Am J Dis Child. (1989) 143:1081-6. doi: 10.1001/archpedi.1989.02150210117030

107. Gonzalez-Heydrich J, Whitney J, Waber D, Forbes P, Hsin O, Faraone SV, et al. Adaptive phase I study of OROS methylphenidate treatment of attention deficit hyperactivity disorder with epilepsy. Epilepsy Behav. (2010) 18:229-37. doi: 10.1016/j.yebeh.2010.02.022
108. Adams J, Alipio-Jocson V, Inoyama K, Bartlett V, Sandhu S, Oso J, et al. Methylphenidate, cognition, and epilepsy: a doubleblind, placebo-controlled, single-dose study. Neurology. (2017) 88:470-6. doi: 10.1212/WNL.0000000000003564

109. Torres A, Whitney J, Rao S, Tilley C, Lobel R, Gonzalez-Heydrich J. Tolerability of atomoxetine for treatment of pediatric attentiondeficit/hyperactivity disorder in the context of epilepsy. Epilepsy Behav. (2011) 20:95-102. doi: 10.1016/j.yebeh.2010.11.002

110. Bernstein GA, Shaw K. Practice parameters for the assessment and treatment of anxiety disorders. J Am Acad Child Adolesc Psychiatry. (1993) 32:108998. doi: 10.1097/00004583-199309000-00044

111. Strawn JR, Mills JA, Sauley BA, Welge JA. The impact of antidepressant dose and class on treatment response in pediatric anxiety disorders: a meta-analysis. J Am Acad Child Adolesc Psychiatry. (2018) 57:23544.e2. doi: 10.1016/j.jaac.2018.01.015

112. Thomé-Souza MS, Kuczynski E, Valente KD. Sertraline and fluoxetine: safe treatments for children and adolescents with epilepsy and depression. Epilepsy Behav. (2007) 10:417-25. doi: 10.1016/j.yebeh.2007.01.004

113. Kanner AM. Most antidepressant drugs are safe for patients with epilepsy at therapeutic doses: a review of the evidence. Epilepsy Behav. (2016) 61:2826. doi: 10.1016/j.yebeh.2016.03.022

114. Alper K, Schwartz KA, Kolts RL, Khan A. Seizure incidence in psychopharmacological clinical trials: an analysis of food and drug administration (FDA) summary basis of approval reports. Biol Psychiatry. (2007) 62:345-54. doi: 10.1016/j.biopsych.2006.09.023

115. Mahajan R, Bernal MP, Panzer R, Whitaker A, Roberts W, Handen B, et al. Clinical practice pathways for evaluation and medication choice for attention-deficit/hyperactivity disorder symptoms in autism spectrum disorders. Pediatrics. (2012) 130:S125-38. doi: 10.1542/peds.2012-0900J

116. Ormond DR, Clusmann H, Sassen R, Hoppe C, Helmstaedter C, Schramm $\mathrm{J}$, et al. Pediatric temporal lobe epilepsy surgery in bonn and review of the literature. Neurosurgery. (2019) 84:844-56. doi: 10.1093/neuros/nyy125

117. Foong J, Flugel D. Psychiatric outcome of surgery for temporal lobe epilepsy and presurgical considerations. Epilepsy Res. (2007) 75:8496. doi: 10.1016/j.eplepsyres.2007.05.005

118. Sobregrau P, Andreu C, Carreño M, Donaire A, Rumià J, Boget T, et al. Psychiatric disorders in patients with resistant temporal lobe epilepsy two years after undergoing elective surgery. A longitudinal study. Epilepsy Behav. (2021) 118:107921. doi: 10.1016/j.yebeh.2021.1 07921

Conflict of Interest: The authors declare that the research was conducted in the absence of any commercial or financial relationships that could be construed as a potential conflict of interest.

Publisher's Note: All claims expressed in this article are solely those of the authors and do not necessarily represent those of their affiliated organizations, or those of the publisher, the editors and the reviewers. Any product that may be evaluated in this article, or claim that may be made by its manufacturer, is not guaranteed or endorsed by the publisher.

Copyright (C) 2021 Vinti, Dell'Isola, Tascini, Mencaroni, Cara, Striano and Verrotti. This is an open-access article distributed under the terms of the Creative Commons Attribution License (CC BY). The use, distribution or reproduction in other forums is permitted, provided the original author(s) and the copyright owner(s) are credited and that the original publication in this journal is cited, in accordance with accepted academic practice. No use, distribution or reproduction is permitted which does not comply with these terms. 